\title{
O uso da citação \\ na peça Dream-Images \\ do Makrokosmos 1 \\ para piano amplificado \\ de George Crumb
}

\section{André de Cillo Rodrigues}

(Universidade de São Paulo)

RESUMO: Este texto propõe uma análise de Dream-Images do compositor George Crumb. Na peça, ocorre uma citação da seção intermediária da Fantasia-Improviso de Chopin. Tomamos como referência conceitual, além de depoimentos do próprio autor no prefácio da partitura de Makrokosmos I, trabalhos recentes sobre a utilização da citação musical como os trabalhos de Simms, Antokoletz, Bukholder e RamautChevassus entre outros. Ao final, comentamos diferenças entre a citação musical antes e depois do século XX e a importância do universo semântico suscitado através da citação de Chopin.

PALAVRAS-CHAVE: Análise musical; Citação musical; Metalinguagem; George Crumb; Século XX.

THE USE OF MUSICAL QUOTATION IN DREAM-IMAGES FROM MAKROKOSMOS I FOR AMPLIFIED PIANO BY GEORGE CRUMB

ABSTRACT: This paper presents an analysis of Dream-Images by George Crumb. In the piece there is a quotation from the middle section of Fantasie-Impromptu by Chopin. The author takes as reference Crumb's own writings in the preface to the score of Makrokosmos I, as well as other recent studies on the use of musical quotation as the works of Simms, Antokoletz, Bukholder and Ramaut-Chevassus among others. At the end, we discuss the differences between musical quotation before and after the $X X$ century and the importance of the semantic universe raised by quoting Chopin.

KEYWORDS: Musical analysis; Metalanguage; Musical quotation; George Crumb; XX century.

1 Este trabalho faz parte de uma pesquisa de mestrado a respeito do uso da citação musical e possui o apoio da FAPESP. 


\section{Introdução}

A série Makrokosmos de George Crumb para piano amplificado compreende dois volumes de 12 peças, cada uma representando um signo do zodíaco. O título alude ao conjunto de peças Mikrokosmos, de Bela Bartok e o formato da obra aos prelúdios para piano de Claude Debussy (Crumb, 1972). O primeiro volume está dividido em três seções de quatro peças devidamente indicadas pela partitura. A última peça de cada seção é grafada na forma de um símbolo (uma cruz, um círculo e uma espiral respectivamente).

O ciclo de peças, de 1972, marca o fim de um período de dez anos sem escrever para o piano. Segundo Cohen (2002, p. 13), “Crumb sentiu a necessidade de explorar o instrumento ainda mais do que ele havia explorado nas cinco peças para piano de 1962". Podemos perceber a intenção de Crumb em explorar algumas possibilidades menos convencionais do piano uma vez que as peças trabalham com sons produzidos diretamente nas cordas, através do uso das unhas, da ponta dos dedos, de dedais e de palhetas de metal. Um microfone situado na região grave altera o timbre e o equilíbrio do instrumento e possibilita a audição das dinâmicas mais tênues (como no caso das muitas indicações de ppppp). O ciclo explora ainda assovios, grunhidos, gritos e o recitar e entoar de palavras durante a interpretação das peças. Neste artigo analisaremos a décimaprimeira peça, intitulada Dream-Images, que representa o signo de Gêmeos.

\section{Análise da décima primeira peça, Dream-Images}

Dream-Images se inicia com um acorde de si maior na região grave do piano. Uma melodia de três notas em torno de lá apresenta o tema da peça e é prontamente respondida por um acorde de fá\# maior (quarta abaixo do primeiro) e uma variação muito sutil da melodia que incorpora uma nova ideia, a apojatura em torno de umas de suas notas (fig.1): 
Figura 1 - Tema

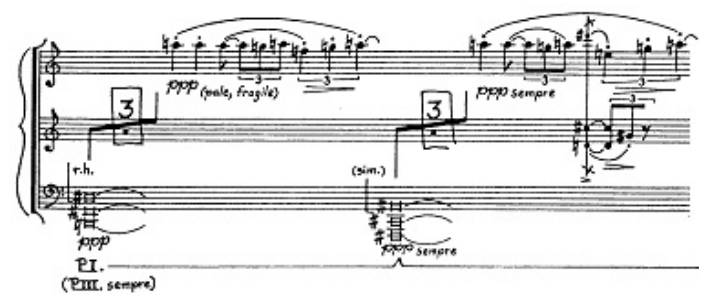

Esta ideia é reapresentada com a diferença de que, agora, a resposta surge transposta uma segunda maior abaixo, uma variação muito efetiva e marcante em um contexto de variações tão tênues. Na quinta vez que aparece, a melodia funciona como ponte para o primeiro aparecimento de uma citação, a parte B da Fantasia-Improviso de Chopin, que surge à medida que o "eco" da melodia precedente se desvanece (fig. 2):

Figura 2- Primeira citação

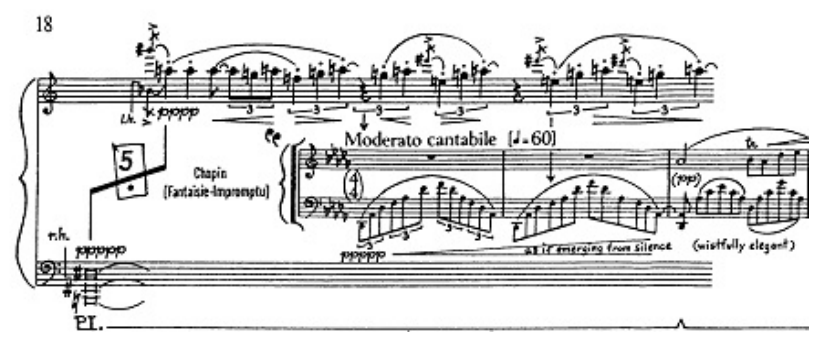

A ressonância das notas presas ao final de cinco compassos de citação se mistura à ressonância do acorde que abre a peça (si maior em posição aberta) e, alguns segundos depois, a melodia recomeça literalmente - já com a adição das apojaturas duplas - e a sua resposta, a variação sutil dela mesma - também com apojaturas duplas - faz a transição para um novo aparecimento da FantasiaImproviso (agora com duração de 4 compassos) através transposições em direção ao registro grave que provocarão consequências fundamentais na peça.

A transição para a segunda citação, como dissemos, provoca consequências à melodia inicial que, muito embora volte a aparecer, desta vez dá origem a novos acontecimentos. Os motivos e ideias musicais precedentes, 
caracterizados por uma imobilidade relativa e por ocuparem uma faixa pequena do campo de tessitura, dão lugar a uma exploração gradualmente maior do campo de tessitura do instrumento iniciada pelo movimento dos acordes em direção ao grave (fig 3):

Figura 3- Segunda citação

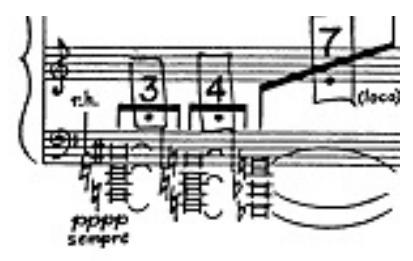

Estes acontecimentos, no entanto, ainda possuem, como os eventos que os precediam, a estaticidade como característica marcante, originada pela repetição de padrões de frequências (fig. 4):

Figura 4- Repetição de padrões de frequências
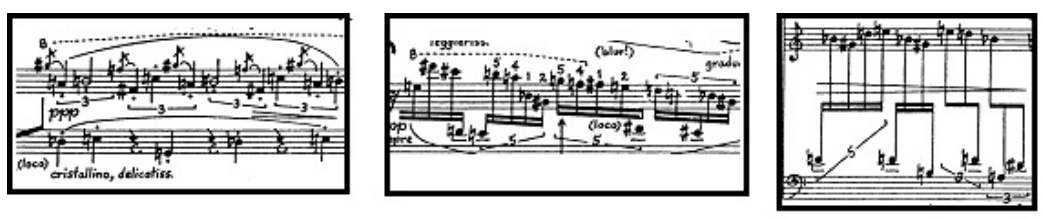

Uma terceira a última citação da Fantasia prepara a volta do acorde e da melodia que abriram a peça, e aqui funcionam como Coda e encerramento da peça ao agregarem por condensação as transformações que ocorreram gradualmente após cada aparecimento da citação (fig. 5):

A memória da melodia inicial, recorrente ao final de cada trecho da citação, ajuda a dar coerência e unidade a uma peça que vinha se desenvolvendo tão lentamente e que foi subitamente contrastada por um material tão heterogêneo como o trecho de Chopin. 
Figura 5- Terceira citação

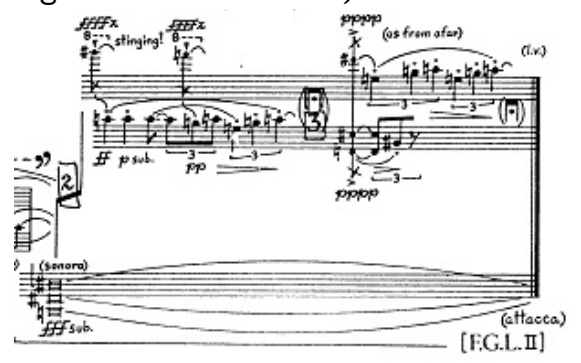

\section{Material motívico e utilização das alturas}

As considerações a seguir a respeito da utilização das alturas na peça Dream-Images se baseiam na observação da partitura e em informações extraídas da leitura de Antokoletz (1996, p. 525) e Lusk (1974, p. 158).

Os materiais motívicos da peça bem como a utilização das alturas provêm do início da primeira peça do ciclo, Primeval Sounds. 14 tríades menores divididas em duas sequências de 7 acordes cada uma se movem ascendentemente partindo da região grave do instrumento. As duas sequências se situam a um trítono de distancia uma da outra e se movimentam por semitons, sendo que uma delas começa com a tríade de si menor e termina com a tríade de fá menor e outra começa com a tríade de fá menor e termina com a tríade de si menor. Os acordes das duas sequências alternam posição fundamental, primeira inversão e segunda inversão (fig. 6):

Figura 6- Sequências de acordes

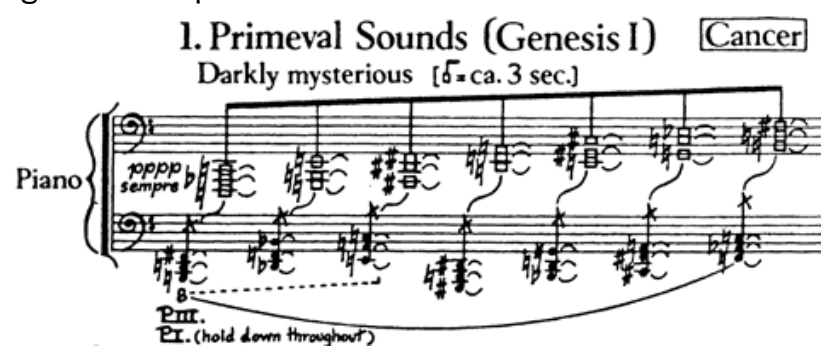


Desta sequência de tríades são extraídos todos os outros materiais de Dream-Images. O primeiro é um motivo melódico formado pelas notas lá, si e fá (e expostas literalmente no início da primeira peça). Este motivo, potencialmente, engloba os intervalos de segunda maior e terça maior, assim como a soma dos dois intervalos, que equivale a um trítono (fig. 7):

Figura 7- Motivo melódico formado pelas notas lá, si e fá
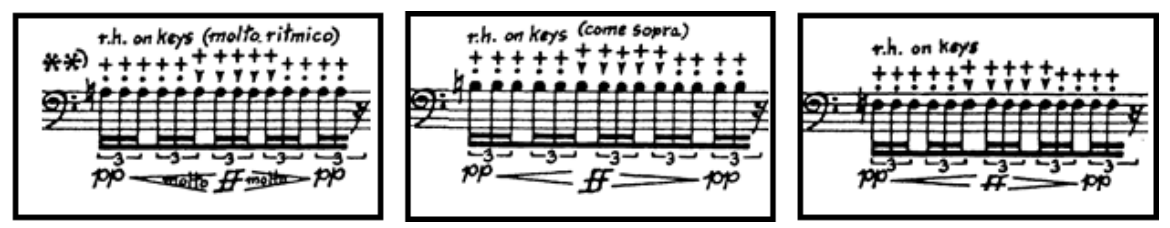

Este motivo é utilizado extensamente em todas as suas formas incluindo retrogradações, inversões e retrogradações invertidas, mostradas na tabela abaixo (Tabela 1):

Tabela 1- Retrogradações, inversões e retrogradações invertidas

\begin{tabular}{llllll}
\hline & \multicolumn{2}{c}{ Original e seu retrógrado } & \multicolumn{3}{c}{ Inversão e seu retrógrado } \\
\hline $\mathrm{A}$ & $\mathrm{B}$ & $\mathrm{F}$ & $\mathrm{A}$ & $\mathrm{G}$ & $\mathrm{CH}$ \\
$\mathrm{Bb}$ & $\mathrm{C}$ & $\mathrm{Gb}$ & $\mathrm{Bb}$ & $\mathrm{Ab}$ & $\mathrm{D}$ \\
$\mathrm{B}$ & $\mathrm{CH}$ & $\mathrm{G}$ & $\mathrm{B}$ & $\mathrm{A}$ & $\mathrm{Eb}$ \\
$\mathrm{C}$ & $\mathrm{D}$ & $\mathrm{Ab}$ & $\mathrm{C}$ & $\mathrm{Bb}$ & $\mathrm{E}$ \\
$\mathrm{Db}$ & $\mathrm{Eb}$ & $\mathrm{A}$ & $\mathrm{CH}$ & $\mathrm{B}$ & $\mathrm{F}$ \\
$\mathrm{D}$ & $\mathrm{E}$ & $\mathrm{Bb}$ & $\mathrm{D}$ & $\mathrm{C}$ & $\mathrm{F} \#$ \\
$\mathrm{~Eb}$ & $\mathrm{~F}$ & $\mathrm{~B}$ & $\mathrm{~Eb}$ & $\mathrm{Db}$ & $\mathrm{G}$ \\
$\mathrm{E}$ & $\mathrm{F}$ & $\mathrm{C}$ & $\mathrm{E}$ & $\mathrm{D}$ & $\mathrm{Ab}$ \\
$\mathrm{F}$ & $\mathrm{G}$ & $\mathrm{CH}$ & $\mathrm{F}$ & $\mathrm{Eb}$ & $\mathrm{A}$ \\
$\mathrm{F \#}$ & $\mathrm{CH}$ & $\mathrm{D}$ & $\mathrm{F} \#$ & $\mathrm{E}$ & $\mathrm{Bb}$ \\
$\mathrm{G}$ & $\mathrm{A}$ & $\mathrm{Eb}$ & $\mathrm{G}$ & $\mathrm{F}$ & $\mathrm{B}$ \\
$\mathrm{Ab}$ & $\mathrm{Bb}$ & $\mathrm{E}$ & $\mathrm{Ab}$ & $\mathrm{Gb}$ & $\mathrm{C}$ \\
\hline
\end{tabular}

Outras variações deste motivo também aparecem com menos frequência. A relação mais comum é entre terça menor e segunda maior (cuja soma pode 
implicar no aparecimento de uma quarta justa) e, mais raramente, aparecem relações entre segunda menor e terça menor. A série e as suas variações são sugeridas pela sequência das notas superiores e inferiores pelas tríades menores mencionadas acima (fig. 8):

Figura 8- Sequências $3 M+2 M$ e $3 m+2 M$

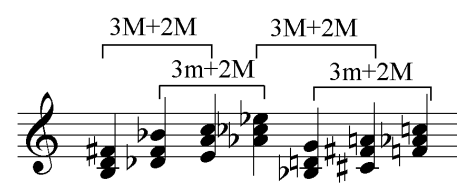

A sequência de fundamentais das tríades também sugere a ênfase nos intervalos de semitom (entre as linhas mostradas na tabela), quarta justa (na diagonal) e trítono (entre as colunas) que pode ser observada muito claramente em Dream-Images assim como em diversos outros momentos do ciclo (tabela 2):

Tabela 2- Seqüência da fundamental das tríades

Sequência da fundamental das tríades

$\begin{array}{llllll}\mathrm{Bb} & \mathrm{A} & \mathrm{Ab} & \mathrm{G} & \mathrm{Gb} & \mathrm{F} \\ \mathrm{E} & \mathrm{Eb} & \mathrm{D} & \mathrm{Db} & \mathrm{C} & \mathrm{B}\end{array}$

Estes materiais explicam a organização das alturas na peça e podem ser percebidos claramente, às vezes de mais de uma maneira, como os acordes no início (fig. 9):

Figura 9- Acordes

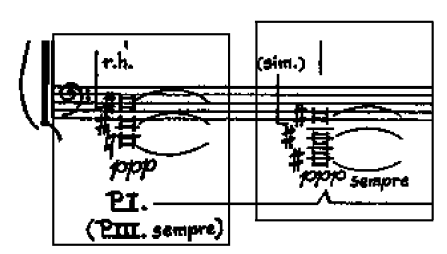


Na figura a seguir, o ré\# do acorde participa de três materiais, do próprio acorde de si maior (quadro maior abaixo), claramente oriundo das tríades menores que abrem o ciclo; como terceira nota da série original a partir da nota sol (primeiro lá bequadro e sol bequadro); e como segunda nota da inversão da série a partir da nota fá (fá bequadro e último lá bequadro) (fig. 10).

Figura 10- Participação da nota ré\# em diferentes materiais

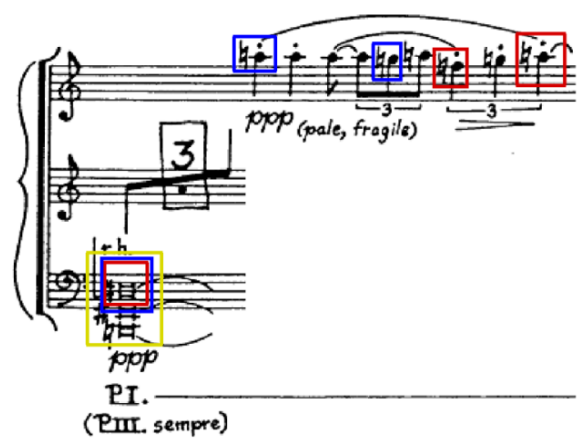

O momento a seguir mostra o motivo original, uma de suas variações e a ênfase sobre os intervalos de trítono, quarta justa e segunda menor, proveniente da série de notas sugerida pela sequencia da fundamental das tríades já mencionada (fig. 11):

Figura 11- Motivo original, uma de suas variações e a ênfase sobre os intervalos de trítono, quarta justa e segunda menor

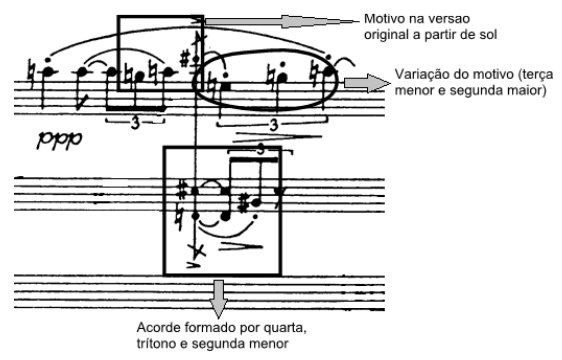


A sequência da fundamental das tríades explica a utilização das alturas em outros momentos, como no arpejo a seguir formado por quartas justas a um semitom de distância (fig. 12):

Figura 12- Arpejo formado por quartas justas a um semitom de distância

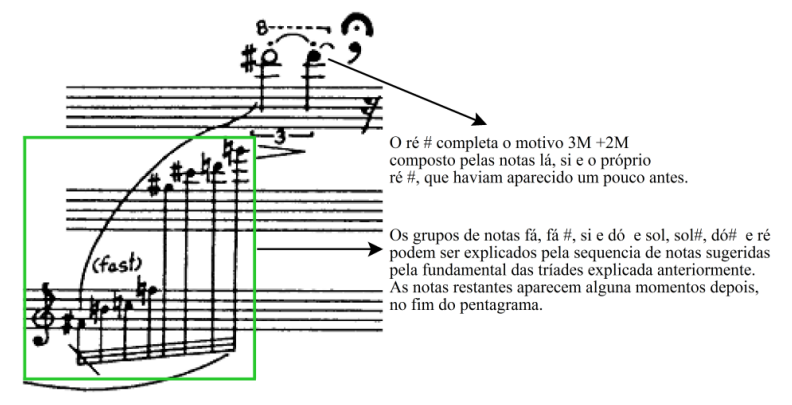

E nos trítonos que aparecem no pentagrama seguinte, que respeitam a ordem de aparecimento da sequência (fig. 13):

Figura 13- Trítonos

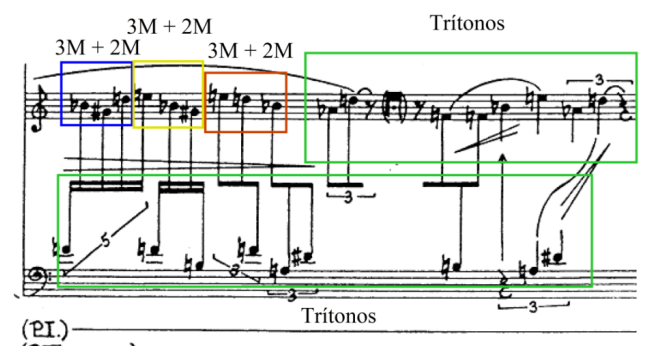

(RII.sempre)

Em outros momentos, podemos perceber o motivo original (amalgamado aos acordes, neste caso) (figs. 14, 15 e 16):

Figuras 14, 15 e 16- Motivo, variação e ambos

A variação:
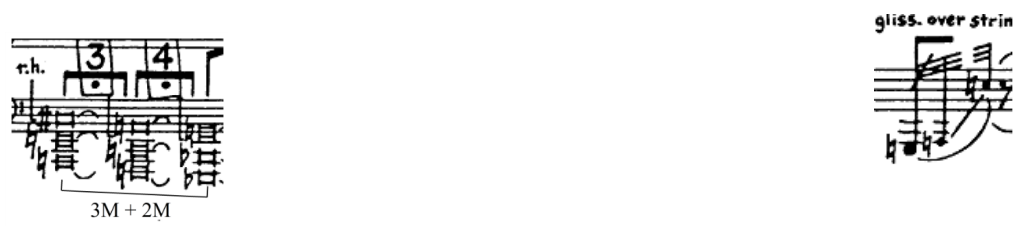
Ou ambos:

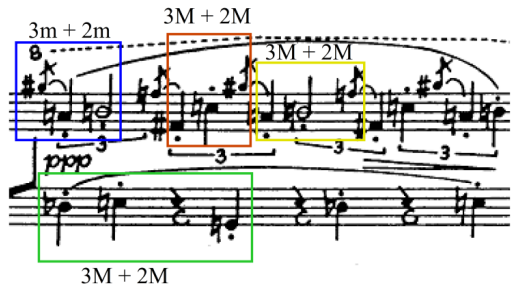

As apojaturas que aparecem ao longo da peça, com exceção da última que é uma variação, sempre sugerem sequencias de semitom (mesmo quando estão a um tom inteiro de distancia da nota principal) (fig. 17):

Figura 17- Apojaturas

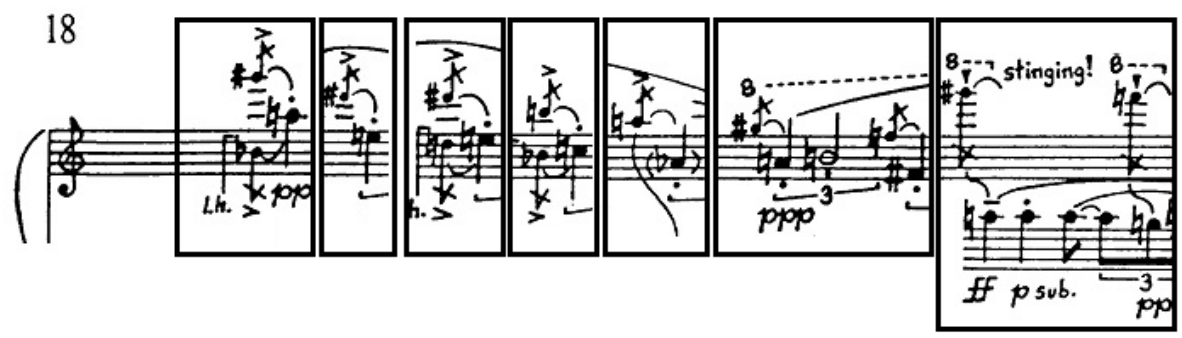

Escalas de tom inteiro, como demonstrado no estudo de Bass (1991, p. 04), podem ser construídas pela concatenação do motivo original lá. si e fá em diferentes transposições e aparecem em Dream-Images em dois momentos (figs. 18 e 19):

Figuras 18 e 19- Escalas de tom inteiro

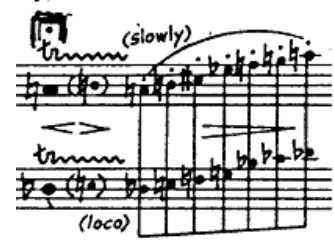

e:

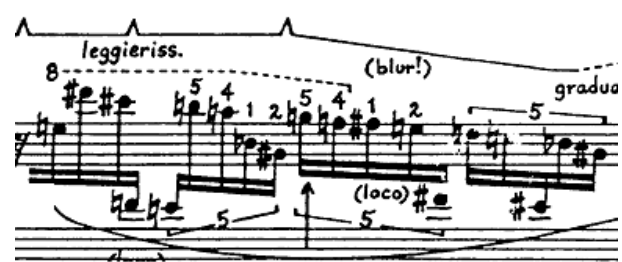

O uso de motivos seriais de poucas notas não é exclusivo de George Crumb. Muito antes dele, Webern já havia construído séries sobre motivos 
intervalares pequenos, como a famosa série construída a partir do motivo BACH. O compositor grego Skalkottas, aluno de Schoenberg, também experimentou a composição de peças a partir de séries de mais e de menos de doze notas, com repetição de notas e até com o uso de mais de uma série simultaneamente, como demonstrado em Rodrigues (2007). A consequência são peças construídas com muita liberdade na distribuição das alturas, ainda mais se considerarmos, neste caso, as variações do motivo lá, si, fá que Crumb utiliza e as outras idéias e princípios unificadores decorrentes da análise do ciclo de peças como um todo. Nada disto compromete a unidade no uso das alturas em Makrokosmos, cujas peças possuem coerência formal e motívica tanto internamente (como vimos em Dream-Images) quanto ao fazerem parte do ciclo (os acordes que abrem o ciclo, por exemplo, surgem recorrentemente durante outras peças, como no início de The Abyss of Time).

\section{Considerações finais}

Como vimos acima, a utilização das alturas privilegia alguns intervalos e pequenas sequencias de notas, e é muito semelhante à utilização das alturas em peças do começo do século $X X$ compostas dentro do chamado atonalismo livre como, por exemplo, as peças para piano opus 11 de Schoenberg.

A relação entre a peça com a citação não é, portanto, relacionada às alturas e poderíamos afirmar que quaisquer relações estabelecidas entre os trechos citados e as partes originais seriam arbitrárias, ao menos no que tange a utilização e distribuição das alturas. Outras relações, como a forma das duas peças, o uso do timbre, das durações ou do perfil das ideias musicais são muito distantes para justificar a utilização específica da Fantasia-Improviso no lugar da citação de outra obra. Desta forma, podemos concluir que a escolha da Fantasia-Improviso se deu por razões extramusicais. Esta hipótese é corroborada por Cohen (2002, p. 14), que escreve:

Às vezes, fatores externos influenciaram a estruturação final da composição. Inicialmente, Crumb havia incluído uma citação das Variações Paganini de 
Rachmaninoff em Makrokosmos I. Entretanto, ao descobrir que elas não estavam em domínio público e que obter permissão legal para usá-las implicaria em um processo legal, ele substituiu-as pela Fantasia-Improviso de Chopin (...) (Cohen, 2002, p. 14).

No contexto em que se insere, a citação é claramente percebida pelo ouvinte, ainda que ele não conheça a Fantasia-Improviso, devido à heterogeneidade dos materiais, construídos em épocas diferentes e com base em sistemas de referencia distintos. A conclusão é que, neste caso, a citação funciona como alusão ao trecho citado e a toda a carga semântica que ele traz, e isso ocorre independentemente de relações estritamente musicais como a relação entre o perfil das ideias da peça citada e da peça citante. Os empréstimos e referencias “(...) podem funcionar como uma palavra, uma imagem. Eles são requisitados pelo seu valor semântico, visto que são empregados em função de um todo que representam. Eles conotam um estilo, uma época, uma obra particular" (RamautChevassus, 1998, p. 98).

Em outras palavras, as associações suscitadas entre a Fantasia-Improviso (citação) e Dream-Images (peça citante), inúmeras e de caráter altamente subjetivo, são trazidas para o primeiro plano por conta do papel de destaque formal que a citação ocupa devido à heterogeneidade dos materiais musicais em si.

A análise de Dream-Images exemplifica uma diferença marcante entre a utilização da citação no século XX e antes dele. Segundo Morgan (1991, p. 411), o emprego da citação musical sempre ocorreu na história da música, embora, excluindo a prática da paródia renascentista, tenha sido relativamente raro até o século XIX. No entanto, "pelo fato das citações musicais no século XIX quase sempre compartilharem um idioma tonal geral com os seus novos contextos, elas tendem a ser cuidadosamente integradas a eles", passando assim quase despercebidas.

Para Bryan Simms (1995, p. 400), a partir do século XX, os compositores encontraram bases para seus próprios trabalhos no trabalho de outros e, apesar da "pronunciada originalidade de muita música no século $X X$ ", teria havido um depósito de confiança muito grande em estilos pré-existentes e em empréstimos 
de músicas passadas, constituindo, desta maneira, um estilo "eclético". Kostka (1999) também aponta o uso crescente de citações, arranjos e paráfrases de música pré-existente no século XX, especialmente a partir de 1960. Burkholder alude ao ecletismo do século XX no verbete Quotation do dicionário Grove Music Online justamente ao dar uma interpretação para a função da citação de Chopin em Dream-Images:

Compositores a partir da Segunda Guerra Mundial utilizaram a citação para sugerir o abismo entre presente e passado ao justapor o idioma musical corrente e passado; em Dream-Images do Makrokosmos I para piano amplificado (1972), a seção intermediária da Fantasia-Improviso de Chopin surge como se emergisse do silencio em meio aos modernos sons docemente dissonantes de Crumb (Burkholder, 2011).

De qualquer modo, a citação musical conota um estilo específico, uma época determinada e uma obra particular, abrindo caminho, a partir do século $X X$, para uma abordagem metalinguística deste fenômeno que ressalte a relação entre a produção musical com a história, sempre levando em conta o universo semântico aludido pelo trecho citado.

\section{Referências}

ANTOKOLETZ, Elliot. Twentieth Century Music. 1. ed. New Jersey: Prentice Hall, 1996.

BASS, Richard. Sets, Scales, and Symmetries: The Pitch-Structural Basis of George Crumb's "Makrokosmos" I and II, Music Theory Spectrum. California: University of California Press. v. 13, n. 1, p. 1-20, 1991.

BURKHOLDER, J. Peter. Verbete "Quotation” in Grove Music online. Disponível em: http://www.oxfordmusiconline.com/subscriber/article/grove/music/52854. Acesso em 19/05/2011.

COHEN, David. George Crumb: a Bio-Bibliography. Westport: Greenwoog Press, 2002.

CRUMB, George. Makrokosmos I. Pennsylvania: Edition Peters, 1972. 1 partitura. Piano.

KOSTKA, Stefan. Materials and Techniques of Twentieth-Century Music. 2. ed. New Jersey: Prentice Hall, 1999. 
LUSK, Larry. Review: Makrokosmos I. Notes, Second Series, Music Library Association . v. 31, n. 1, p. 157-158, 1974.

MORGAN, Robert P. Twentieth-Century Music: A History of Musical Style in Modern Europe and America (The Norton Introduction to Music History). 1. ed. New York: W. W. Norton \& Company, 1991.

RAMAUT-CHEVASSUS, Beátrice. Musique et pos-modernité. Paris: PUF, 1998.

RODRIGUES, André de Cillo. A Aplicação do Método Dodecafônico. Anais do $15^{\circ}$ SIICUSP. São Paulo, 2007.

SIMMS, Bryan R. Music of the Twentieth Century: Style and Structure. 2. ed. New York: Schirmer Books, 1996. 